\title{
Management of a Pediatric Subtrochanteric Fracture with PHILOS Plating - A Case Report
}

\author{
Mohit Jindal ${ }^{1 *}$, Keerty Garg ${ }^{2}$, Nishant Kumar ${ }^{1}$, Shashank Agarwal ${ }^{3}$ and Vibhav Gandhi ${ }^{1}$ \\ ${ }^{1}$ Department of Orthopaedics, Kalpana Chawla Govt Medical College, India \\ ${ }^{2}$ Deparment of anaesthesia, Kalpana Chawla Govt Medical College, India \\ ${ }^{3}$ Department of Orthopaedics, ESI PGIMSR New Delhi, India \\ *Corresponding author: Mohit Jindal, Assistant Professor, Department of Orthopaedics, Kalpana Chawla Govt Medical College, India
}

Submission: 海 March 12, 2018; Published: 㱕 May 23, 2018

\begin{abstract}
Pediatric hip fractures are very rare and comprise only about 1 percent of all pediatric fractures [1]. Of all pediatric hip fractures rarest is the subtrochanteric hip fracture [2] for which no definite treatment guidelines are available. Different treatment options are used: skin traction, 90/90 skeletal traction, spica casting, cast bracing, internal fixation and external fixation. Patient age, weight, femoral canal size, fracture stability, associated injuries, and surgeon's experience should all be considered when determining the best treatment option. Infants 0-6 months of age are well treated with a Pavlik harness. Children 6 months to 5 years of age should be treated with a hip spica cast, although internal fixation is a viable alternative if the fracture is unstable. But children more than 6 years is where the dilemma starts. There is no definite concensus on treatment and all have their own sets of complications. Unlike management of adult subtrochanteric fractures, internal fixation devices for the treatment are not so readily available for pediatric population. Pediatric DHS and Reconstruction plating [3] are some options that are available but both are lacking in stability as the fracture pattern is not addressed in both these options. Internal fixation device like TENS nailing is available but are applicable only to fractures below the subtrochanteric region. External fixation and casting are other methods but have their own set of complications and issues with social acceptance of these methods. We have used an adult Proximal humerus PHILOS plate to address a pediatric subtrochanteric fracture in a 10 year old adolescent girl child and found excellent results after a 3 month follow up and propose to add the same as a viable treatment option in management of such cases.
\end{abstract}

Keywords: Subtrochanteric fracture; Children; PHILOS plate

\section{Introduction}

Femoral shaft fractures, including subtochanteric and supracondylar fractures, represent approximately $1 \%$ of all bony injuries in children [1]. Paediatric subtrochanteric femoral fractures are rare and have received limited attention in the literature [2]. The subtrochanteric femoral fracture in children is a special type which occurs 1 to $2 \mathrm{~cm}$ below the lesser trochanter. The proximal fragment tends to flex (ilio-psoas), abduct (abductor group) and rotate externally (short external rotators). The treatment of subtrochanteric femoral fractures in children is controversial. Different treatment options have been used: skin traction, 90/90 skeletal traction, immediate spica casting, cast bracing, internal fixation and external fixation. Treatment choices are influenced by the child's age and size and whether the femoral fracture is an isolated injury or part of a polytrauma and disadvantages of any operative procedure are also important factors .Generally infants 0-6 months of age are well treated with a Pavlik harness. Children 6 months to 5 years of age should be treated with a hip spica cast, although internal fixation is a viable alternative if the fracture is unstable. But children more than 6 years is where the dilemma starts. There is no definite concensus on treatment and all have their own set of complications. Besides unstable fractures definite indications for operative treatment include multiple trauma, head injury, open fracture, floating knee, vascular or neurological injuries, failure of conservative treatment, older child or adolescent and social indications [4,5]. Methods of fixation include; intramedullary nails, compression plating and external fixator.

We have used an adult Proximal Humerus PHILOS plate to address a pediatric subtrochanteric fracture in a 10 year old adolescent girl child and found excellent results after a 3 month follow up and propose to add the same as a viable treatment option in management of such cases.

\section{Case Report}

A 10 year old girl came to our emergency with history of Road traffic accident with complain of painful swelling around left hip. There was no associated history of loss of consciousness, 
ENT Bleed, vomiting etc present. Physical examination revealed a tender swelling left hip and restricted movements around Left Hip. Skiagram was done which revealed an intertrochanteric fracture with subtrochanteric extention. Immediate splintage was given and relevant investigations and necessary blood work was done and patient posted for surgery for the next day Figure 1.

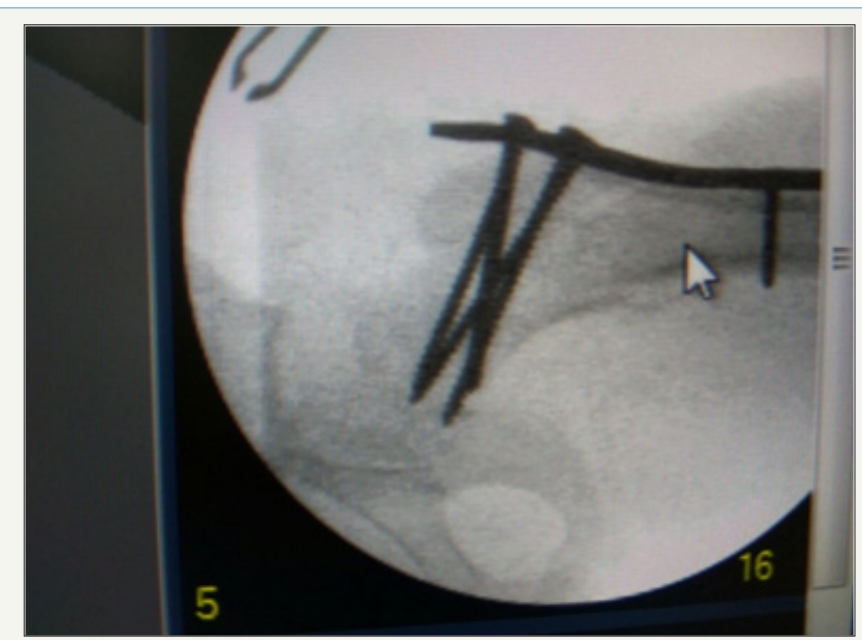

Figure 1: Intra operative fluoroscopy AP view of the fractured hip with implant in position.

\section{Surgical technique}

One unit of blood was made available. Intra operative traction was used and surgery was carried under fluoroscopy guidance. Under spinal anaesthesia, a posterolateral muscle splitting approach was used. Minimal soft tissue dissection and periosteal elevation were done. Indirect reduction and distraction was attempted for reduction, correction of angulation and restoration of length. A single precontoured PHILOS Plate was used and multiple 4.5 locking cancellous screws inserted along the femoral neck .Other cortical screws were inserted using multiple stab incisions like as described for MIPPO Technique. This confers advantage over reconstruction plate as the plate is already precontoured and nultiple screws can be inserted in the femoral neck unlike a reconstruction plate which only allows for a single 6.5 cancellous screw insertion in the neck. Moreover this can be performed using MIPPO technique unlike a reconstruction plate.

No casts were used postoperatively. Crutch-assisted walking with limited weight-bearing was allowed ten days postoperatively and full weight bearing after six to twelve weeks. Hip range of motion and quadriceps exercises were started while the patient was in the hospital. Clinical and radiological assessment of the patient included duration of healing, alignment, presence or absence of postoperative infection, hip and knee motion, leg length discrepancy, and functional daily activities.

\section{Discussion}

Paediatric subtrochanteric femoral fractures present a special unstable type which receives no special attention in the literature. Patient's age may be the most important single variable regarding paediatric femoral fracture treatment. The treatment for children between the ages 6-12 years is the most controversial. Treatment options include traction followed by hip spica cast, immediate spica casting, cast bracing, internal fixation and external fixation. Traction followed by hip spica cast is the method preferred by many surgeons for the treatment of children aged 6-10 years [6]. However, this method requires a relatively long hospitalization and accurate control of fracture alignment with frequent radiographs and adjustment in traction as needed. 90/90 skeletal traction with post traction spica is not suitable in children weighing more than $45 \mathrm{~kg}$ or in children older than 10 years of age as it will be associated with an unacceptable high incidence of femoral shortening and malrotation [7]. Immediate spica casting, popularized by Staheli \& Sheridan [8] is indicated for isolated femoral shaft fractures in children under 6 years of age.

Several studies have documented superior results with internal fixation compared to non operative treatment [9]. Paediatric subtrochanteric femoral fractures are difficult to maintain in an accepted position by non operative means. Methods of internal fixation of paediatric subtrochanteric fractures include intramedullary nails, compression plating and external fixators. Awareness of the advantages and disadvantages of intramedullary nails, compression plates and external fixator and the skill to apply each method safely are requisites to the ideal management of such fractures. Good results were reported with external fixators, but the rates of pin tract infection, refracture and loss of reduction are high [10]. We prefered not to use the external fixator in the treatment of paediatric subtrochanteric femoral fractures as there is no sufficient room for application of the pins into the proximal femoral fragment. Flexible intramedullary nailing is nowadays the treatment of choice in paediatric femoral fractures. Patients are able to partially weight bear early because a rod is a load-sharing device, there is rapid fracture healing and a low incidence of malunion and non union Disadvantages of intramedullary nailing are lack of rotational control, exposure to irradiation and backing out of implant. Fixation of subtrochanteric fractures in children using intramedullary nails need special experience and may be difficult to achieve. Plate fixation, despite the negative report of Ziv \& Rang [11], has been shown to work well in the paediatric age group The disadvantage of plating are the need for plate removal, poor cosmetic appearance of the scar, blood loss associated with exposure and reduction of the fracture and reported higher degree of overgrowth induced by the plates compared with intramedullary fixation. On the other hand, patients treated with a plate require less assistance, can walk with crutches within ten days postoperatively and return to school sooner than children treated in 90/90 skeletal traction.

Most of the earlier studies have used either Dynamic compression plates [12]. Reconstruction plates for fixation of pediatric subtrochanteric fractures, but neither of these plates are structurally precontoured and have to be moulded intra operatively so as to conform to the pediatric hip, but PHILOS plates are pre confirmed to proximal humerus which is similar to the pediatric hip with an already precontoured bend which fits snugly to the greater trochanteric eminence of femur. 
Also these plates have options for inserting locking screws at angle of 130 degress which is at par with the pediatric hip and multiple neck screws can be inserted via this. However on the contrary Dynamic compression plates and Reconstruction plates only allow for a single cancellous non locking screw to be inserted, Hence the construct is less stable theoretically as compared to PHILOS plate. Also PHILOS plates can be inseted via MIPPO technique which allows for minimal soft tissue dissection, minimal periosteal stripping and hence less vascular damage and small surgical scars as compared to other plates.

\section{Conclusion}

Internal fixation with a PHILOS plate appears as a good treatment option for subtrochanteric femoral fractures in children.

\section{References}

1. Kasser JR, Beaty JH (2007) Femoral shaft fractures. In: Rockwood and Wilkins' fractures in children. (6 $6^{\text {th }}$ edn), Acta Orthopædica Belgica 73(4): 490.

2. Ireland DC, Fisher RL (1975) Subtrochanteric fractures of the femur in children. Clin Orthop 110: 157-166.

3. Sayed MEL, Abulsaad M, Hadidi MEL, Eladl W, Batouty MEL (2007) Reconstruction plate fixation of subtrochanteric femoral fractures in children. Acta Orthop Belg 73: 484-449.
4. Kregor PJ, Song KM, Routt ML, Sangeorzan BJ, Liddell RM, et al. (1993) Plate fixation of femoral shaft fractures in multiply injured children. J Bone Joint Surg Am 75(12): 1774-1780.

5. Ligier JN, Metaizeau JP, Prevot J, Lascombes P (1998) Elastic stable intramedullary nailing of femoral shaft fractures in children. J Bone Joint Surg Br 70(1): 74-77.

6. Tolo VT (2000) Treatment of fractures of the long bones and pelvis in children who have sustained multiples injuries. J Bone Joint Surg 82: 272-280.

7. Reeves RB, Ballard RI, Hughes JL (1990) Internal fixation versus traction and casting of adolescent femoral shaft fractures. J Pediat Orthop 10(5): 592-595.

8. Staheli, LT, Sheridan GW (1977) Early spica cast management of femoral shaft fractures in young children : a technique utilizing bilateral fixed skin traction. Clin Orthop Relat Res (126): 162-166.

9. Humberger FW, Eyring EJ (1969) Proximal tibial 90-90 traction in treatment of children with femoral-shaft fractures. J Bone Joint Surg 51(3): 499-504.

10. Gregory P, Pevny T, Teague D (1996) Early complications with external fixation of pediatric femoral shaft fractures. J Orthop Trauma 10(3): 191-198.

11.Ziv I, Rang M (1983) Treatment of femoral fractures in the child with head injury. The Journal of Bone and Joint surgery 65: 276-278.

12. Ward WT, Levy J, Kaye A (1992) Compression plating for child and adolescent femur fractures. J Pediat Orthop 12(5): 626-632.
Creative Commons Attribution 4.0 International License

For possible submissions Click Here

\section{Submit Article}

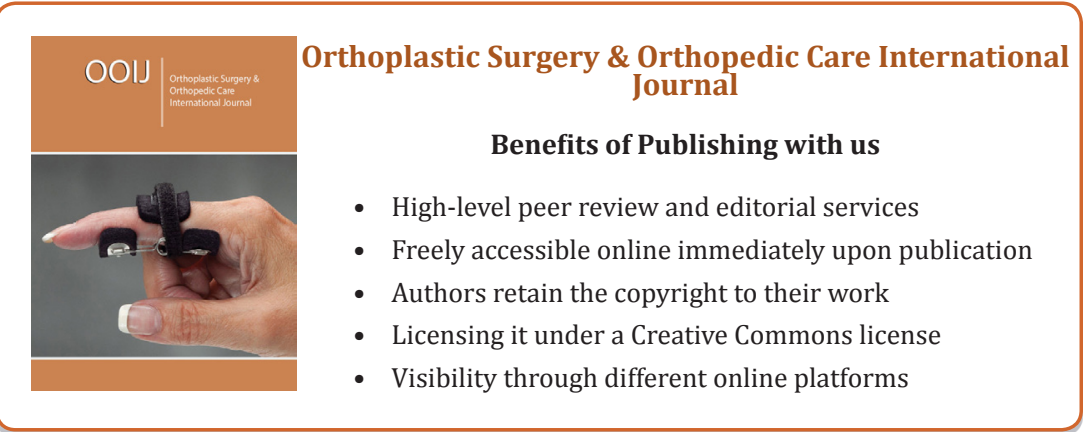

